\title{
الرقابة القضائية على عنصر السبب في قرارات الضبط الإداري
}

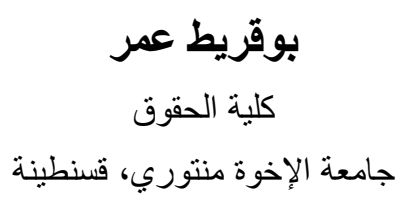

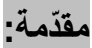

يعتبز الضبط الإداري من الأنشة

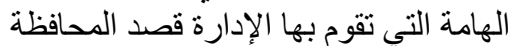

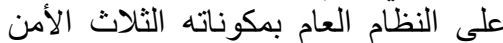

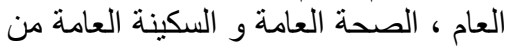

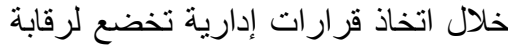

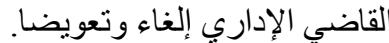

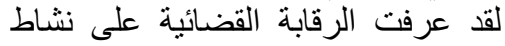
الإدارة تطورات كبيرة وهامة في القوانئ الفين

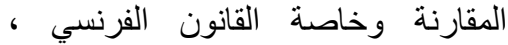

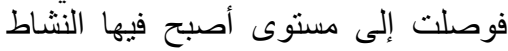

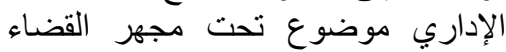

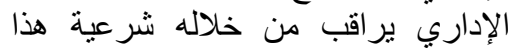

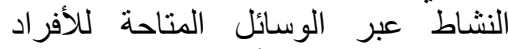

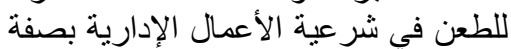

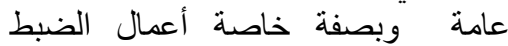

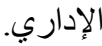

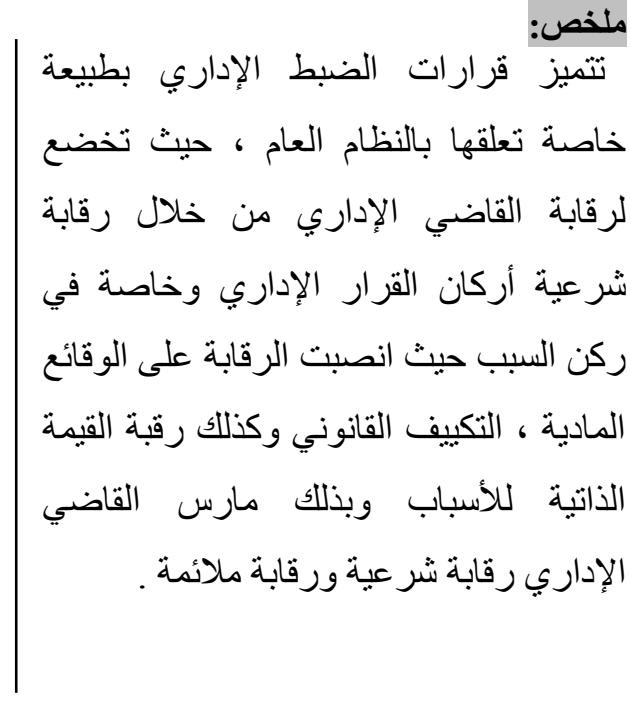

\section{Abstract :}

Les mesures de police administrative ont une nature spécifique, tirée de leur finalité qui est celle de servir l'intérêt générale. ces mesures sont soumises au contrôle de juge administratif qui apprécie la légalité des éléments constitutifs de ces mesures de police et particulièrement les motifs , ce contrôle touche également les faits matériels, la qualification juridique ainsi que la valeur intrinsèque des motifs, le juge administratif exerce un contrôle de légalité et un contrôle d'opportunité sur certains aspects des mesures de police administrative 
إن تدابير الضبط الإداري لا تعدو أن تكون قرارات إدارية تتوفر فيها العناصر المكونة للقرار الإداري

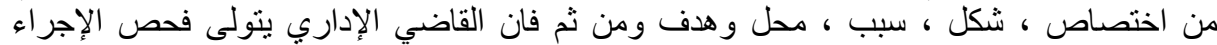

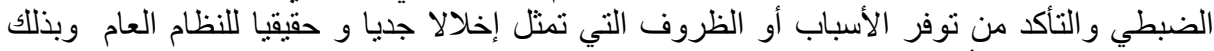

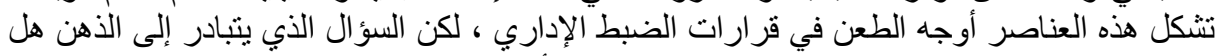

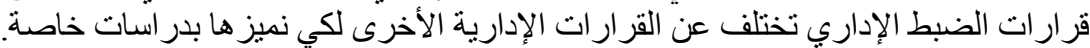

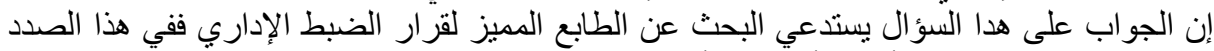

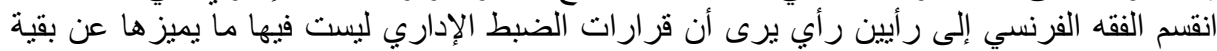

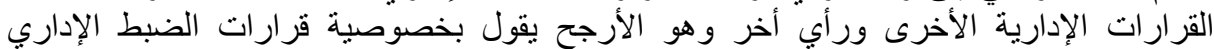

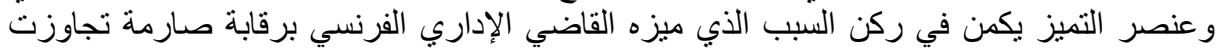

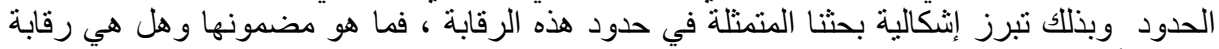

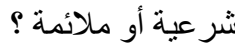
وقد تم تقسيم الموضوعة إلى محورين,محورين ، الأول نتناول فيه محتوى الرقابة ومحور يخصص

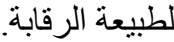

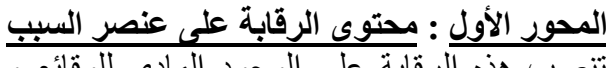

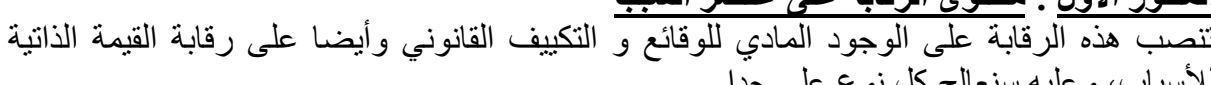

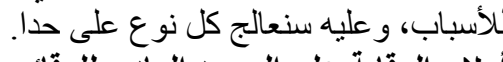

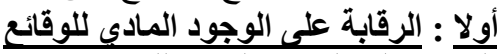

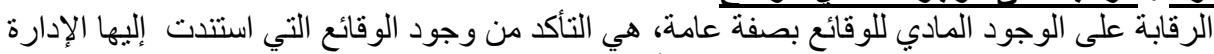

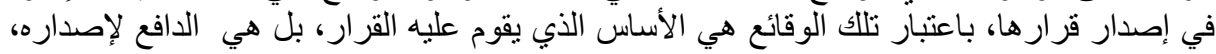

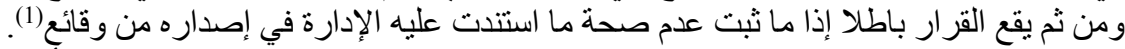

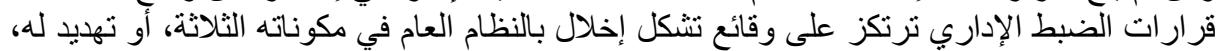

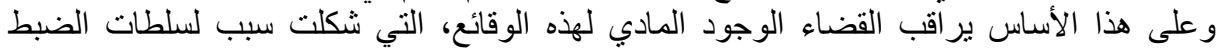

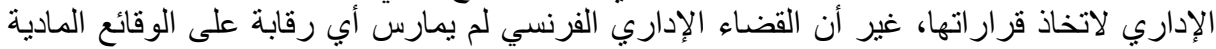

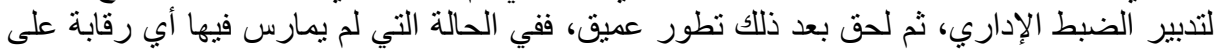

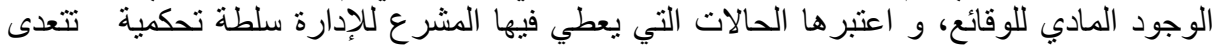

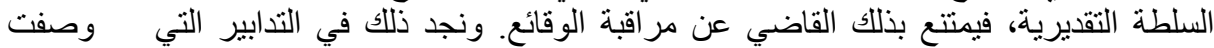
بالضبط الأعلى (Haute police) التي تتخذ تطبيقا للقوانين التي لها صفة استنثائية وبذللك تخول

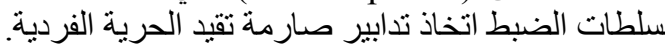

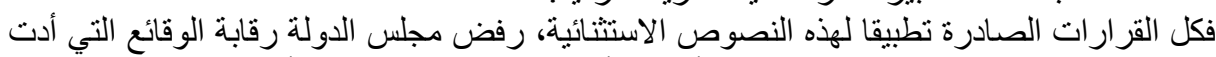

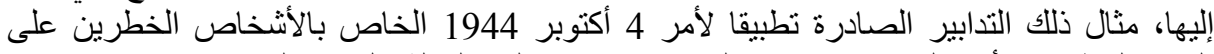

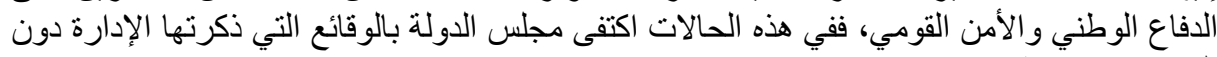

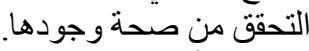

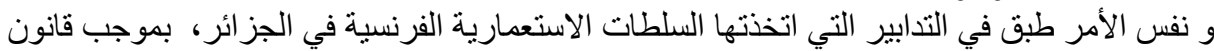

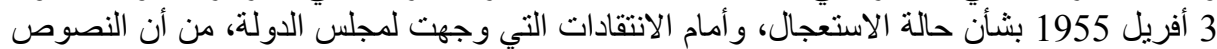

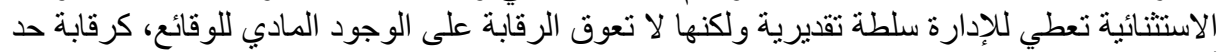

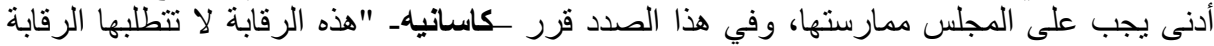

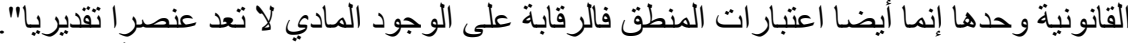

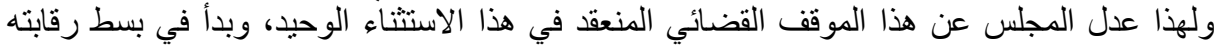

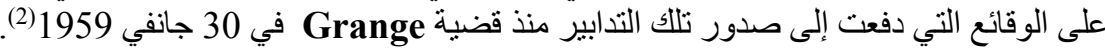

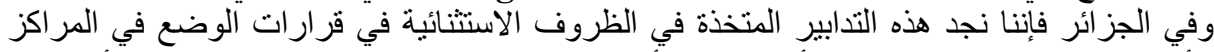

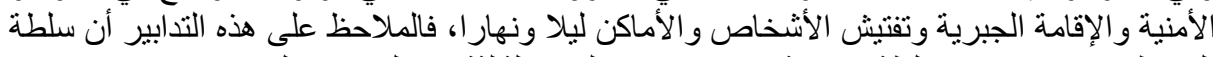

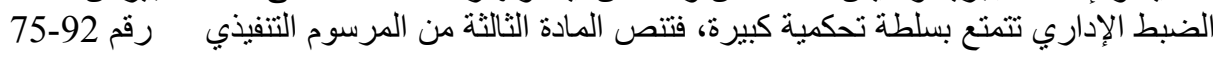




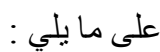

"يتخذ تدبير الوضع في مركز أمن وزير الداخلية والجماعات المحلية أو السلطة التي يفوضهاويتخذ

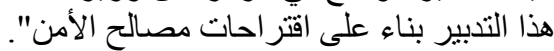

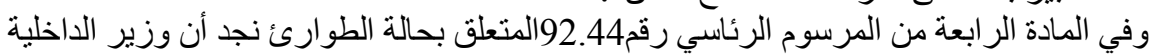

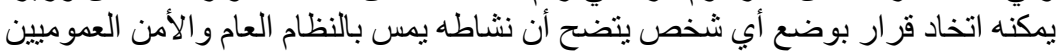

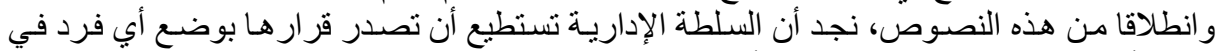

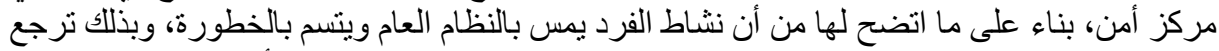

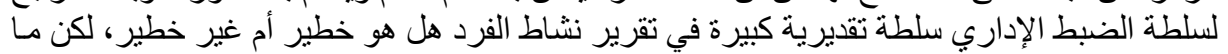

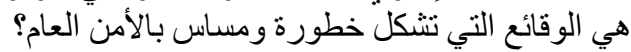

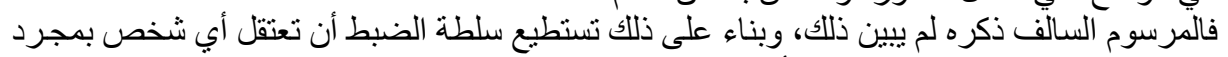

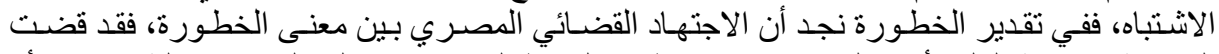

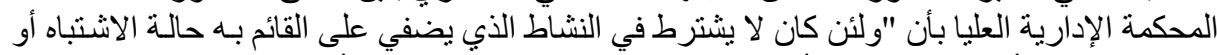

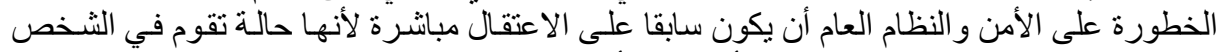

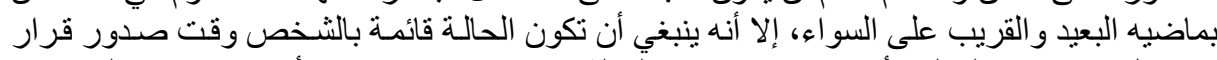

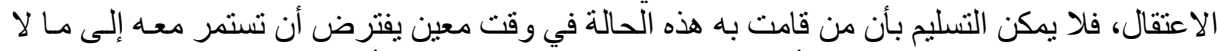

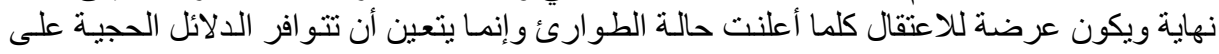

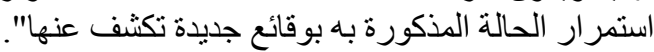

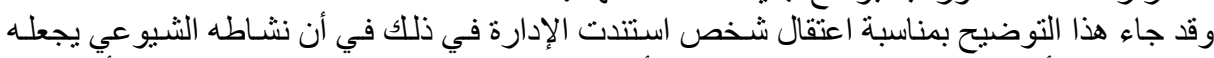

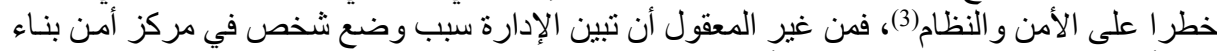

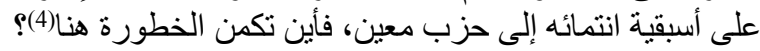

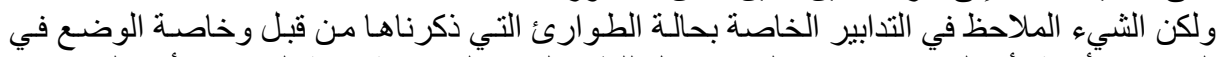

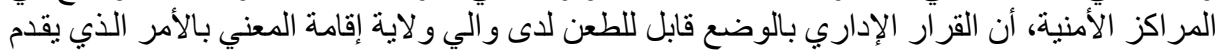

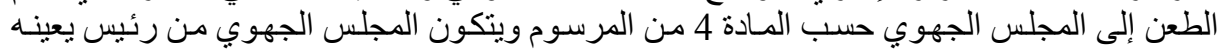

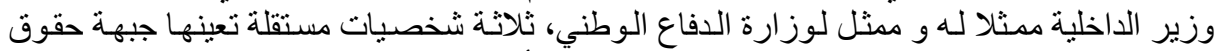

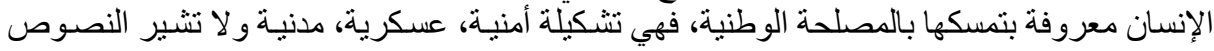

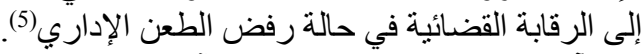

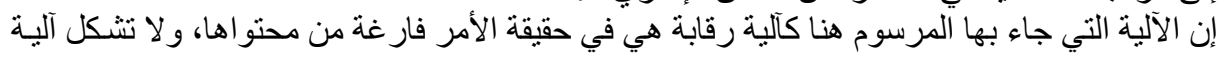

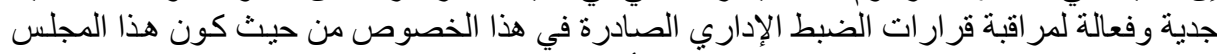

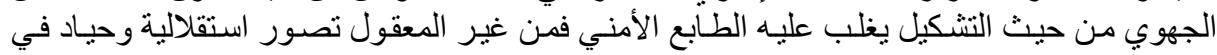

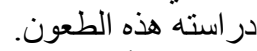
ومن جهة أخرى كان بالأحرى النص في المرسوم على الرقابة القضائية عن طريق الطعن بالإلغاء

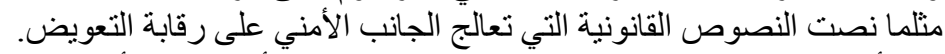

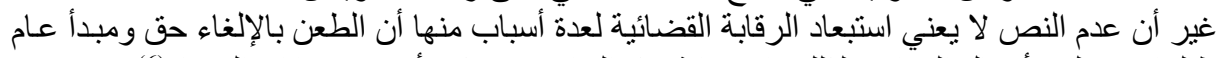

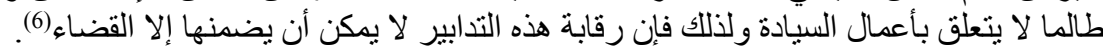

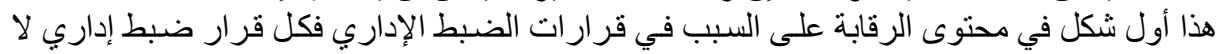

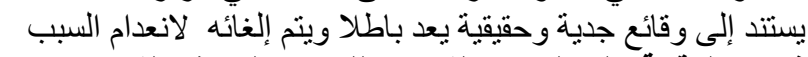

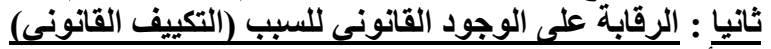

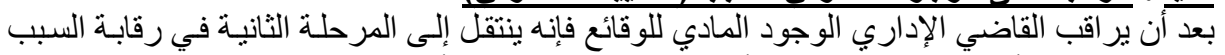

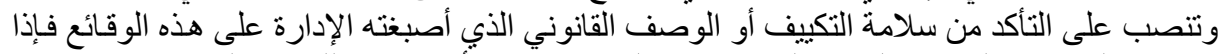

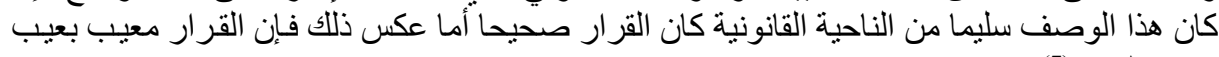

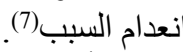
وقد بـدأ مجلس الدولـة الفرنسـي في مباشـرة هذا النـوع مـن الرقابـة عندما أصـدر حكمـه الثـهير 


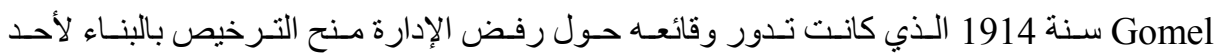

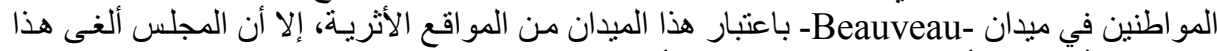

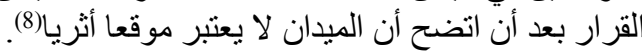

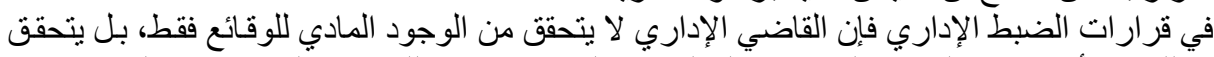

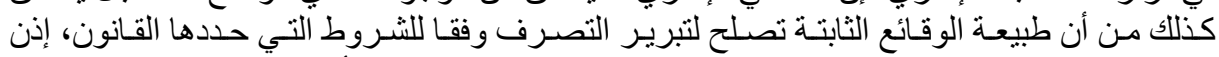

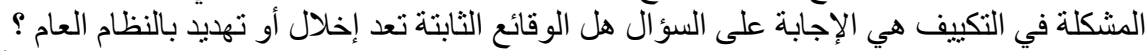

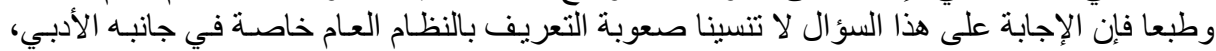

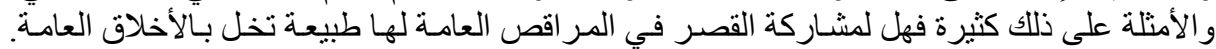

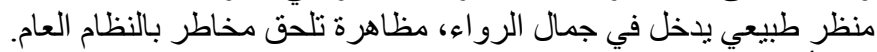

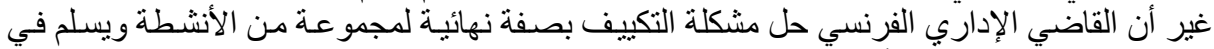

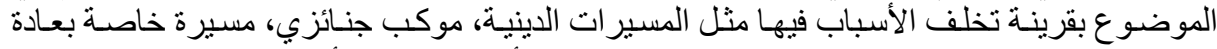
محلية، الصلاة الجماعية في مكان طلق، فمجلس الدولة هنا أقام قرينة على أن المسيرات الدير الدينية لا تهدد

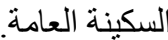

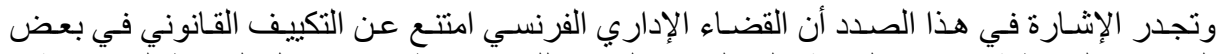

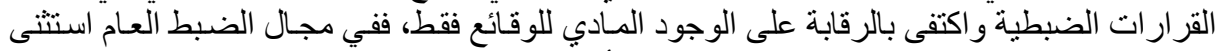

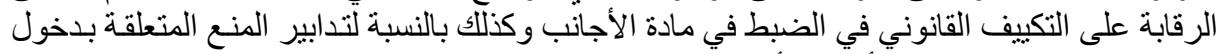

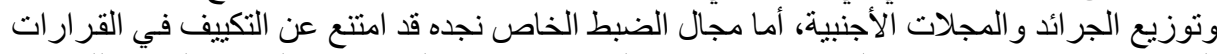

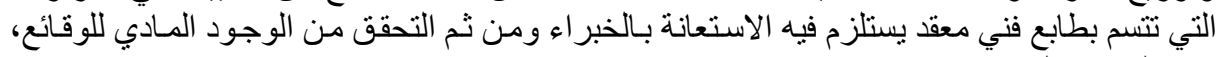

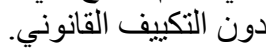

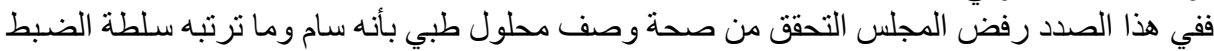

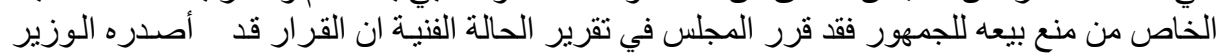

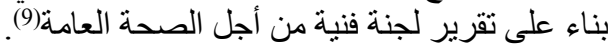

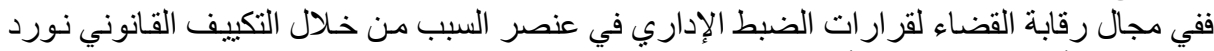

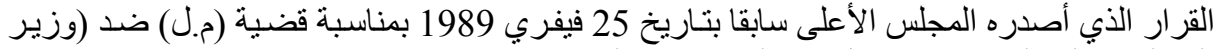

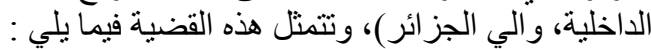

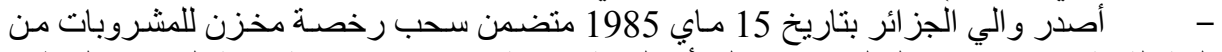

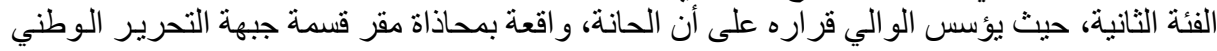
بالقبة وفي منطقة محمية.

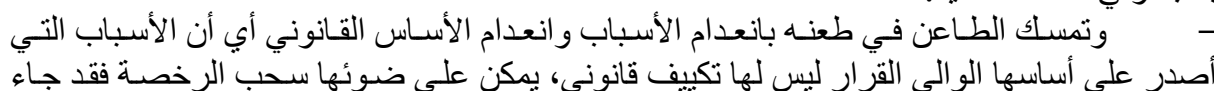

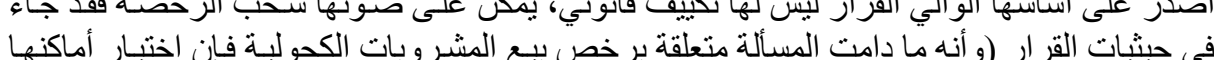

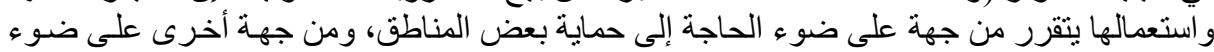

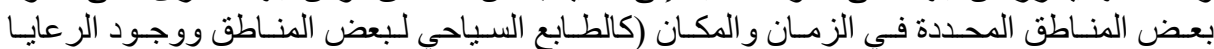

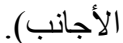

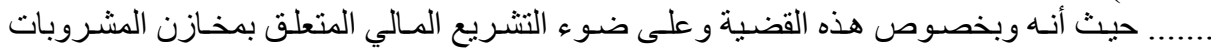

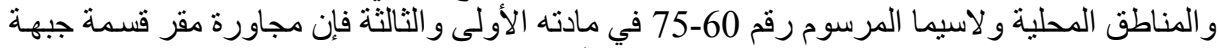

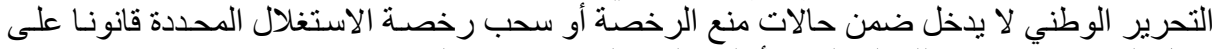

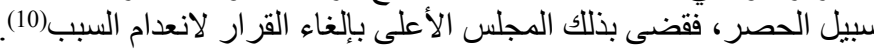

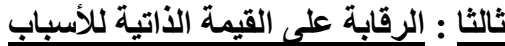

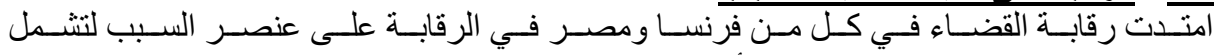

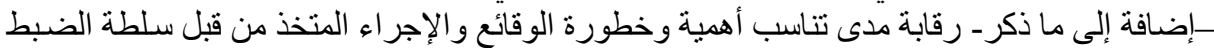

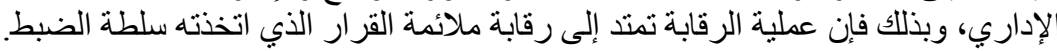


فقد وجد مجلس الدولة الفرنسي أن رقابته التقليدية على سبب القرار الضبطي المتثنلة في رقابة الوجود

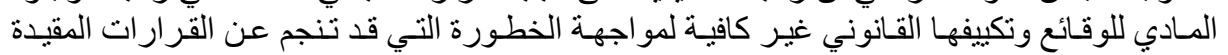

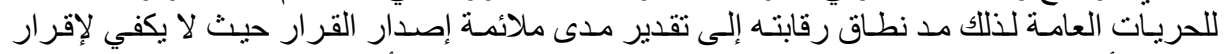

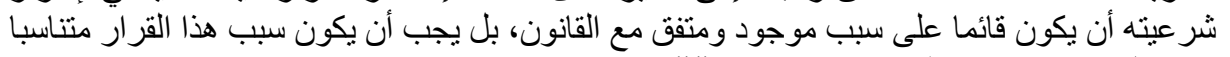

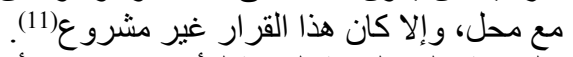

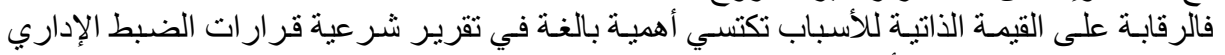

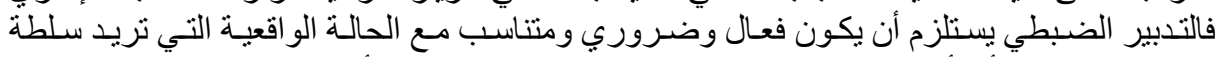

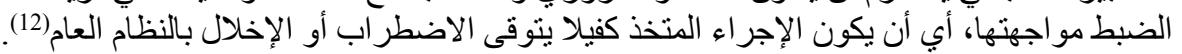

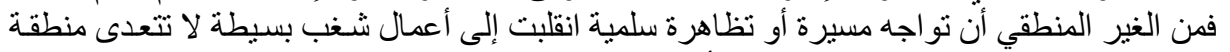

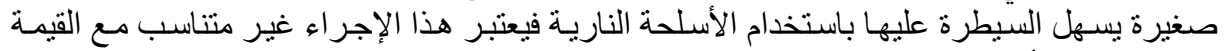

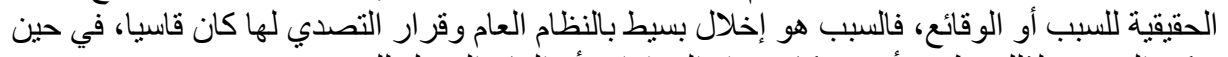

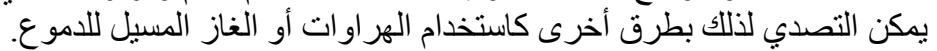

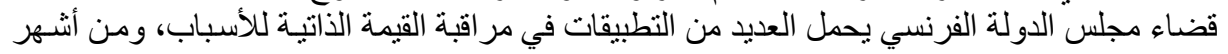

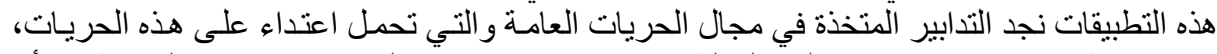

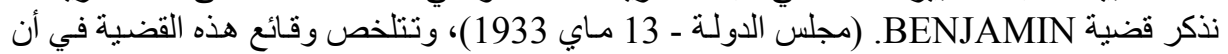

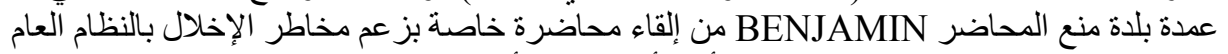

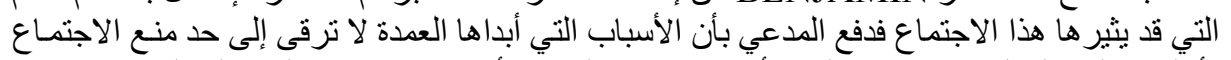

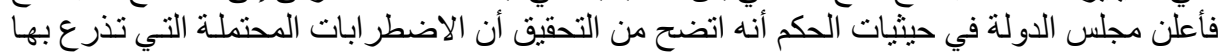

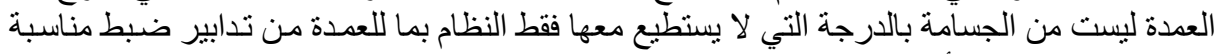

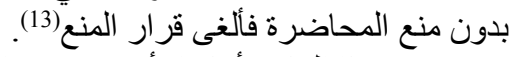

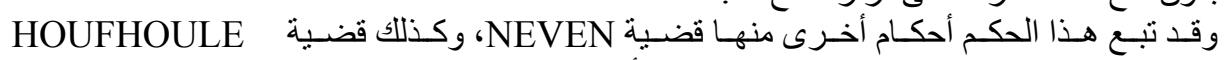

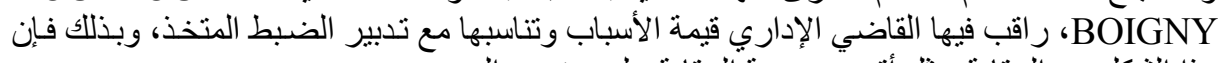

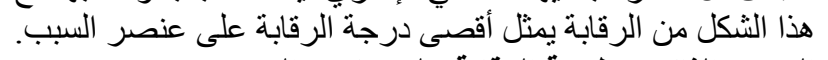

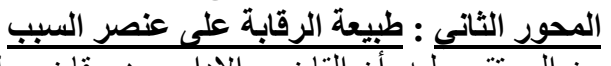

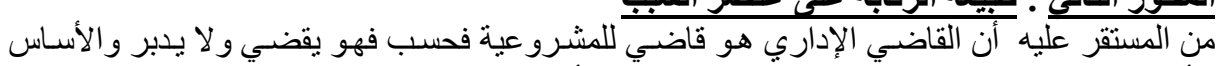

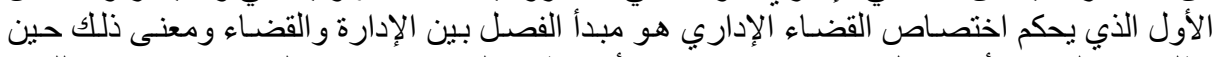

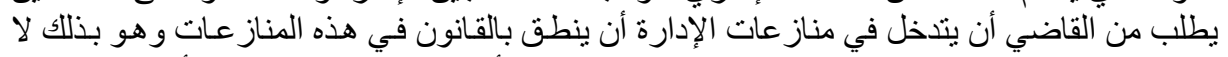

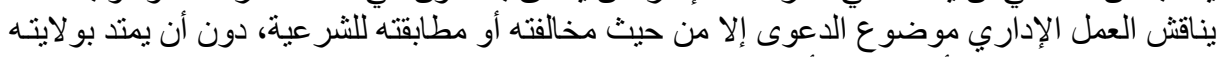

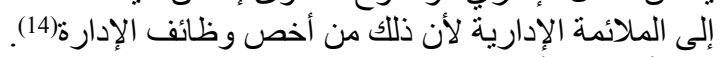

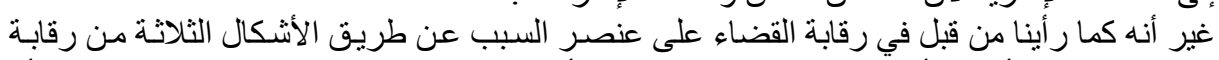

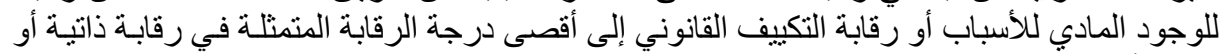

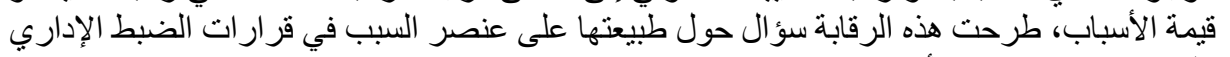

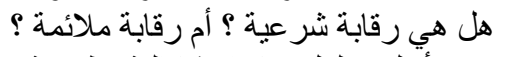

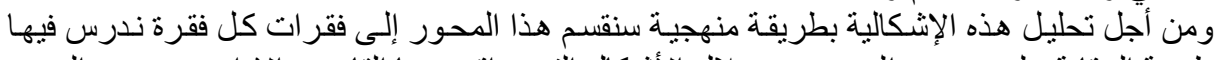

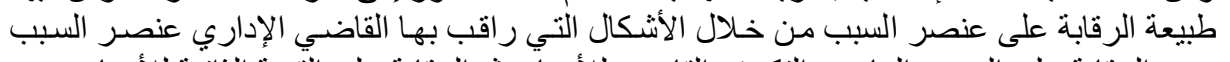

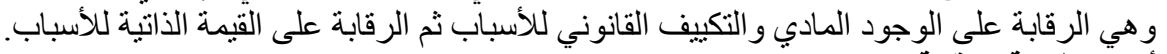

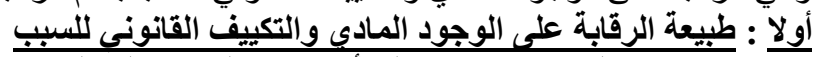

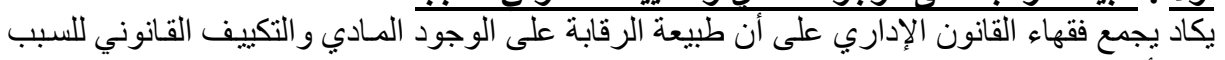
على أنها رقابة شر عية.

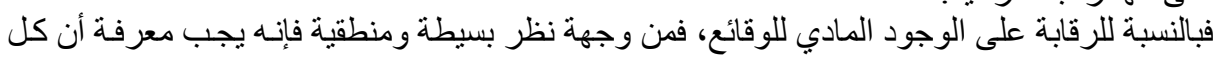

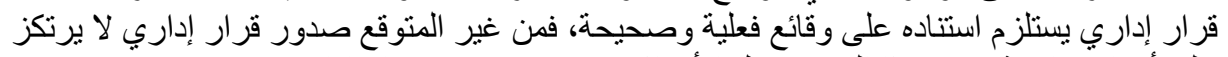
على أسباب و اقعية، وفي هذا الصدد يقول الأستاذ BONNARD "قرار إداري بدون سبب لا لا يعتد بـه 
وبذلك فإن لزوم السبب هو مبدأ أساسي له قيمة مبدأ شرعي، وبذلك فيان القرار بدون سبب يكون غير

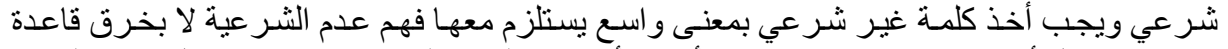

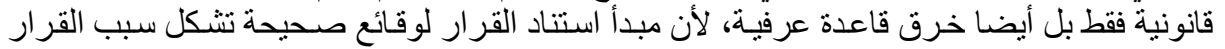

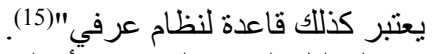

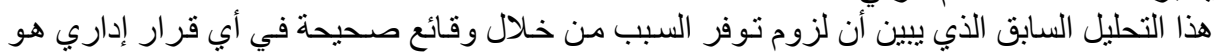

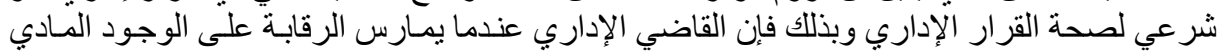

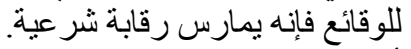

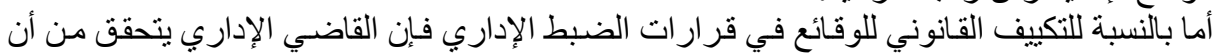

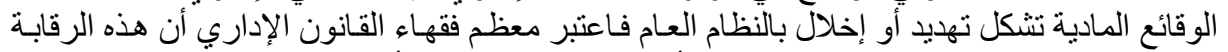

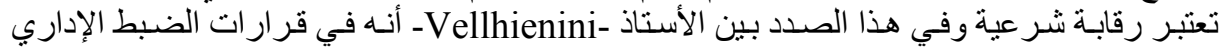

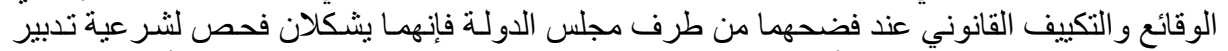

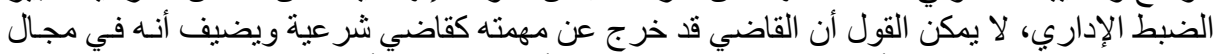

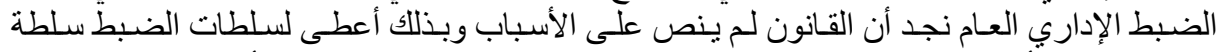

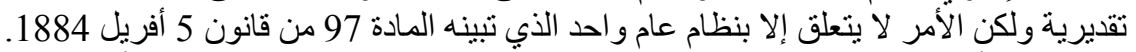

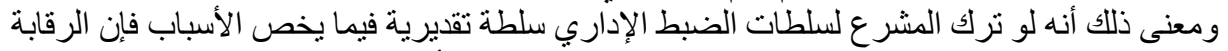

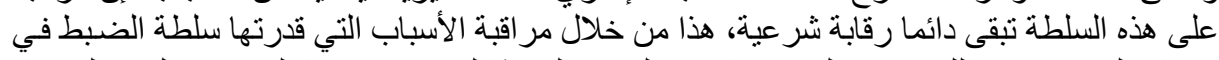

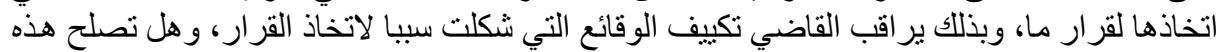

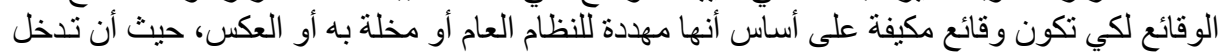

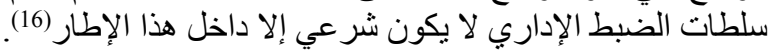

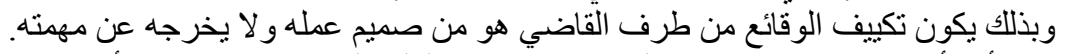

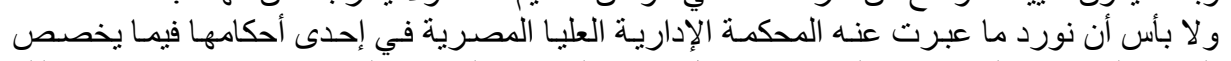

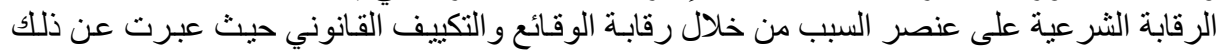

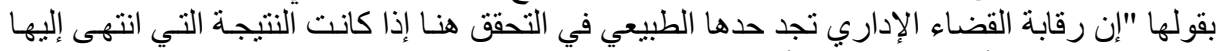

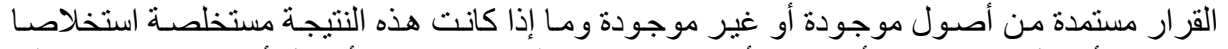

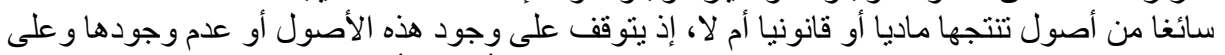

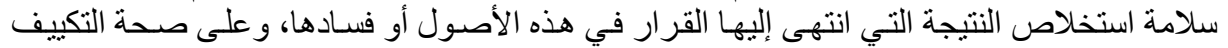

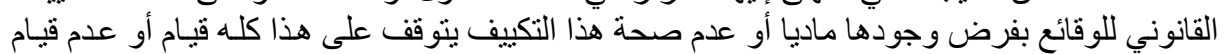

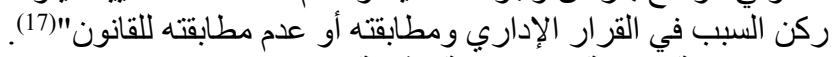

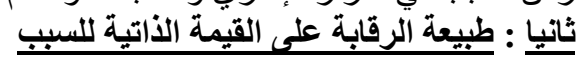

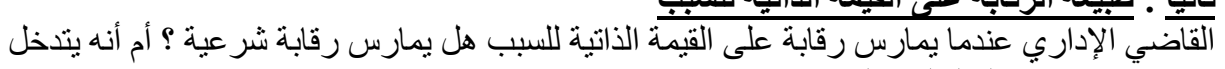

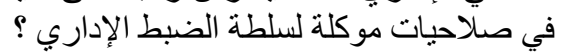

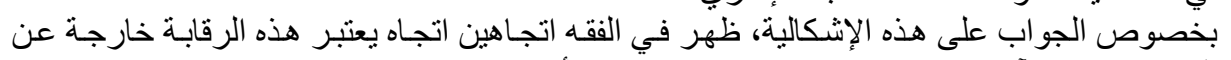

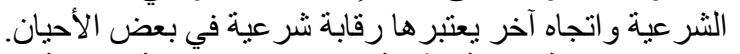

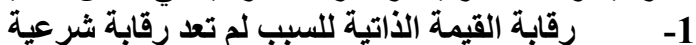

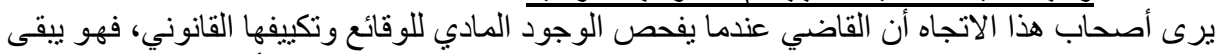

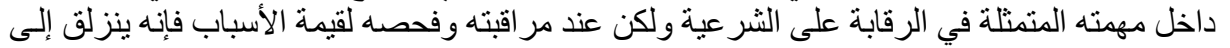

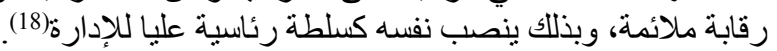

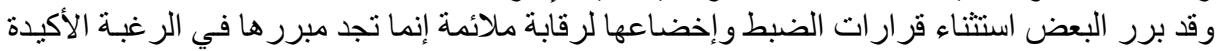

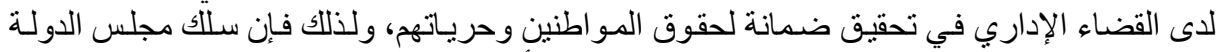

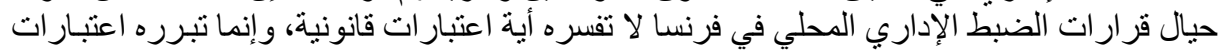

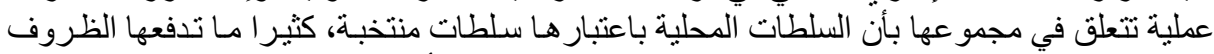

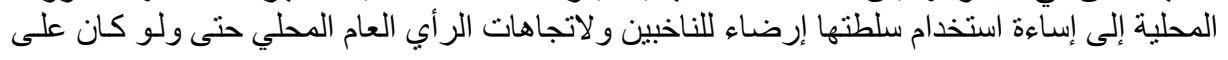


حساب الحريات العامة أحيانا(19).

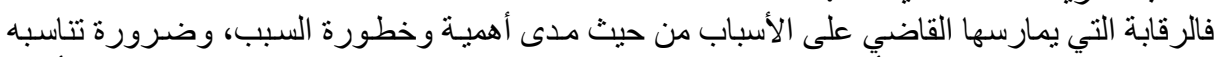

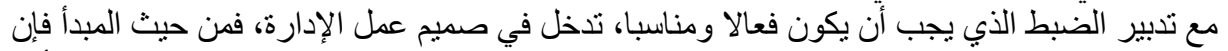

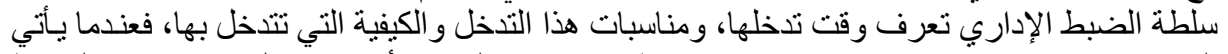

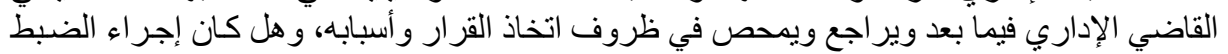

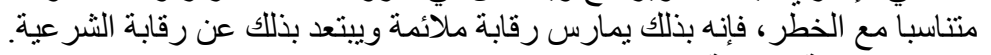
2-

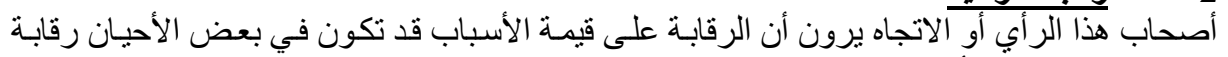

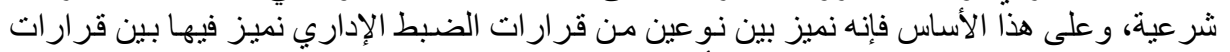

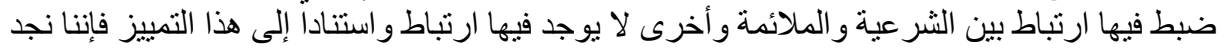

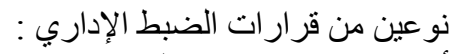

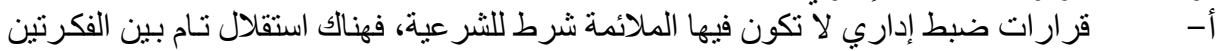

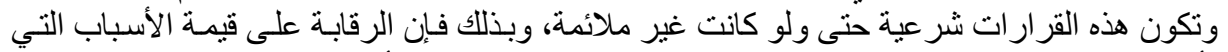

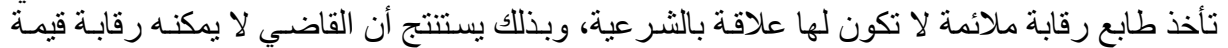

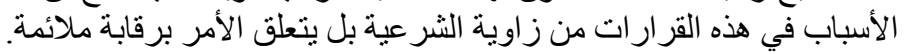

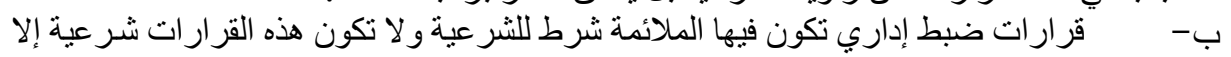
إذا كان بيتوفر فيها عنصر الملائمة.

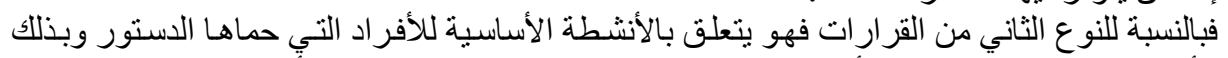

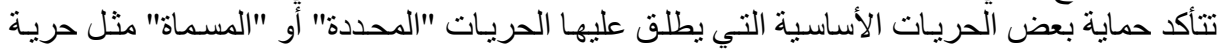

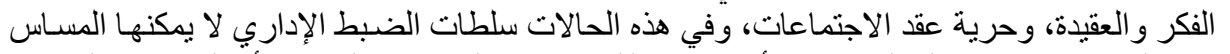

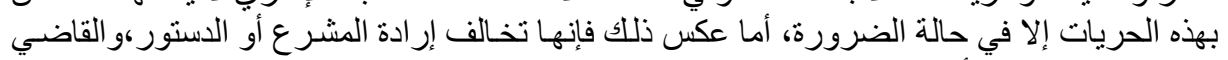

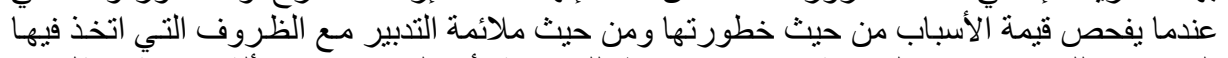

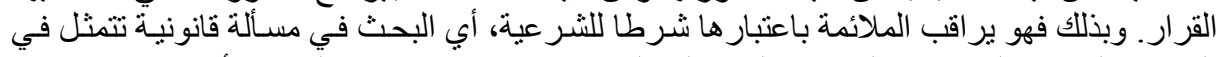

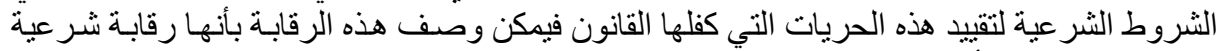
على القيمة الذاتية للأسباب.

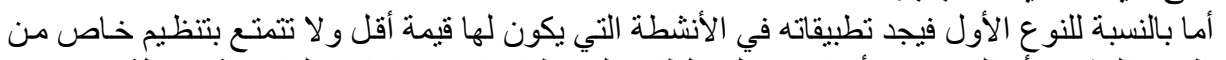

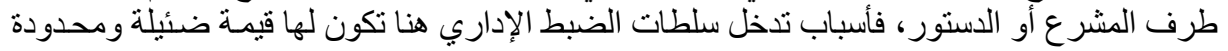

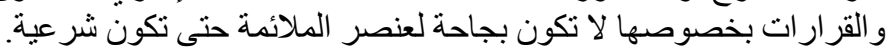

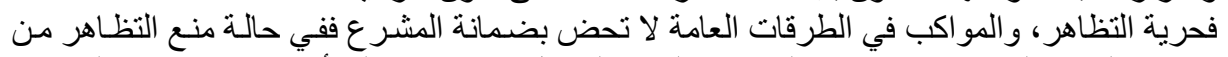

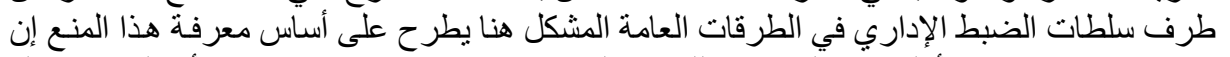

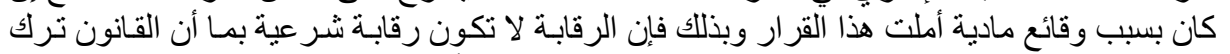

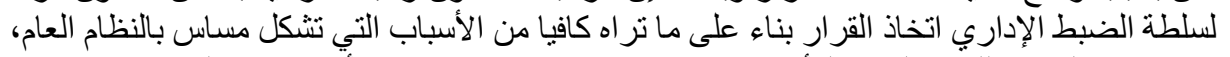

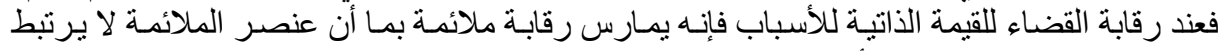

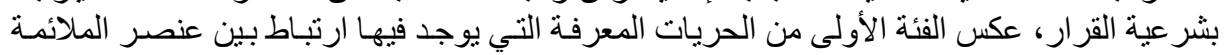
و الشر عية(20).

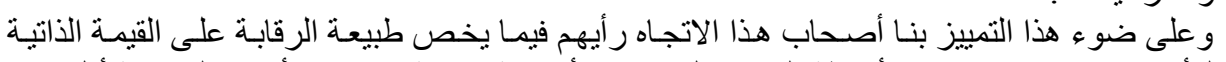

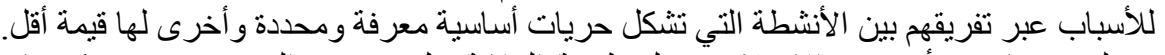

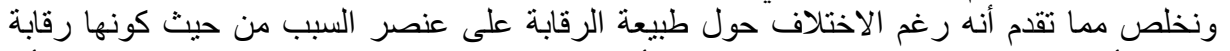

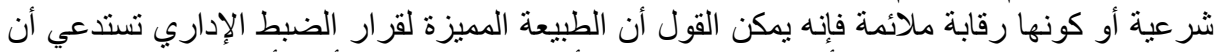

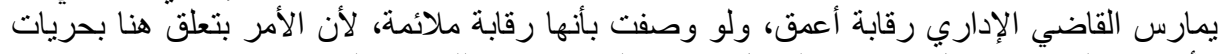

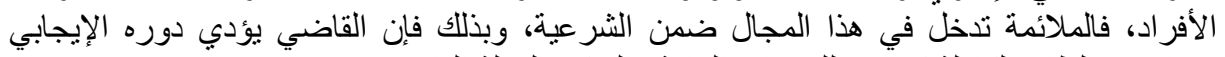

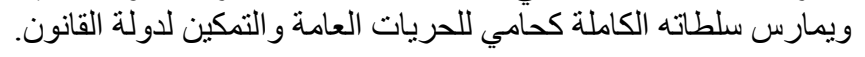


الخاتمة

إن تعلق قرار ات الضبط الإداري بالمحافظة على النظام العام وتمتع الإدارة بسلطات واسعة في عملية

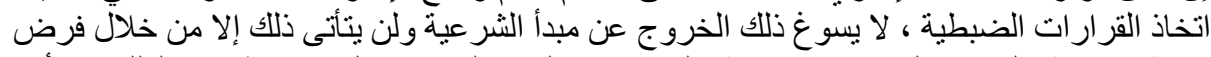

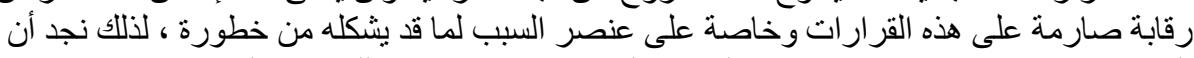

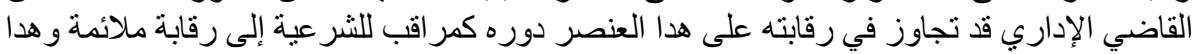

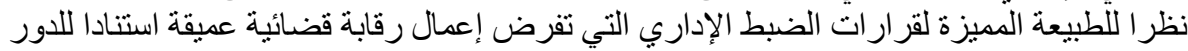

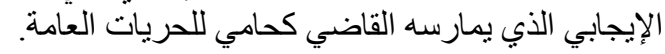

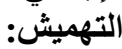

1- عبد العزيز عبد المنعم خليفة، الانحر اف بالسلطة كسبب لإلغاء القرار الإداري، مصر، دار الفكر

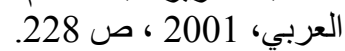

2- الدقدوقي حلمي، رقابة القضاء على المشروعية الداخلية لأعمال الضبط الإداري، مصر، دار

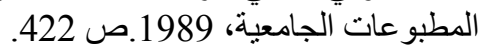

3- عرفت الجزائر هذا النوع من الاعتقال في سنة 1992 باعتقال منال مناضلين الحزب المنحل (الجبهة

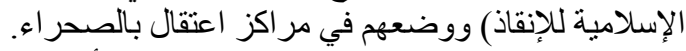

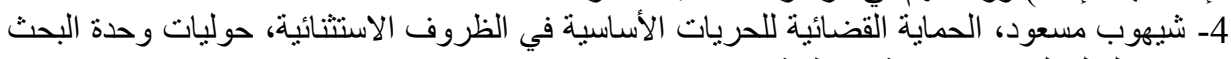

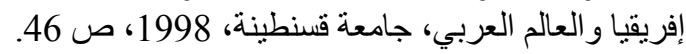

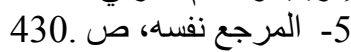
6- المرجع نفسه، نفس الصفحة.

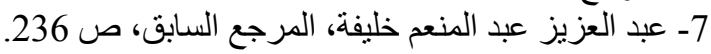
8- الدقدوقي حلمي، رقابة القضاء على على المشروعية الداخلية لأعمال الضبط الإداري، مصر، دار

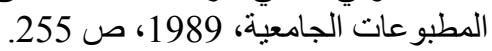

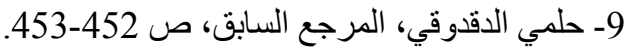

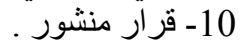

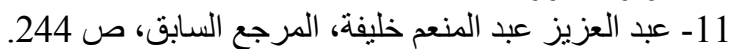

12- البنا عاطف محمد، الوسيط في القانون الإداري، الطبعة الثنانية، القاهرة، دار الفكر العربي، 1992،

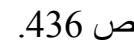

13- البنا محمود عاطف، حدد سلطات الضبط الإداري، مجلة القانون و الاقتصاد، مطبعة جامعة القاهرة،

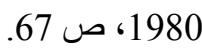

14- سامي جمال الدين، وسيط القانون الإداري، مصر مطابع الطويجي التجارية، 1993ص 15-Jean Castagne, le contrôle juridictionnel de la légalité des actes de police, Paris, librairie générale de droit et de jurisprudence, 1964. p 176.

16- Ibid. p177.

17- بسيوني عبد الغني عبد الله، القضاء الإداري قضاء الإلغاء، مصر، منشأة المعارف، 1997، ص

18- Jean Castagne. Op. Cit. p 180.

19- محمود عاطف البنا (حدود سلطة الضبط الإداري)، المرجع السابق، ص 69.

20- Jean Castagne. Op. Cit. p 187. 